\title{
Immunoassay of $S$-adenosylmethionine and S-adenosylhomocysteine: the methylation index as a biomarker for disease and health status
}

Xiujuan Hao ${ }^{1 *}$, Yan Huang ${ }^{3}$, Ming Qiu ${ }^{5,6}$, Chunlin Yin ${ }^{4}$, Huiming Ren ${ }^{2}$, Hongjie Gan ${ }^{2}$, Huijun Li ${ }^{2}$ Yaxia Zhou ${ }^{2}$, Jiazhi Xia ${ }^{2}$, Wenting Li ${ }^{3}$, Lijuan Guo ${ }^{4}$ and Isaac A. Angres ${ }^{1}$

\begin{abstract}
Background: S-Adenosylmethionine (SAM) and S-adenosylhomocysteine $(S A H)$ are relevant to a variety of diseases. Previous reports that quantified SAM and SAH were based on HPLC or LC-MS/MS. No antibody against SAM has been generated, and the antibody against SAH cannot be used with blood samples. Immunoassays have not been used to measure SAM and SAH. In this study, ELISA was used to measure blood SAM and SAH levels.

Results: Specific antibodies against SAM were produced for the first time using a stable analog as the antigen. The monoclonal antibodies against SAM and SAH were characterized. No cross-reactivity was detected for the analyzed analogs. For the anti-SAM antibodies, the ELISA sensitivity was $\sim 2 \mathrm{nM}$, and the affinity was $7.29 \times 10^{10} \mathrm{~L} / \mathrm{mol}$. For the anti-SAH antibodies, the sensitivity was $\sim 15 \mathrm{nM}$, and the affinity was $2.79 \times 10^{8} \mathrm{~L} / \mathrm{mol}$. Using high-quality antibodies against SAM and SAH, immunoassays for the detection of SAM and SAH levels in blood and tissue samples were developed. Clinical investigations using immunoassays to measure SAM, SAH and the methylation index (MI) in normal and diseased samples indicated that (1) the SAM level is age and gender dependent; (2) the SAM level is associated with the severity of liver diseases, inflammatory reactions and other diseases; and (3) the methylation index (MI) is significantly reduced in many diseases and may serve as a screening biomarker to identify potentially unfavorable health conditions.

Conclusion: It is possible to generate antibodies against active small biomolecules with weak immunogenicity, such as SAM and SAH, using traditional hybridoma technology. The antigens and antibodies described here will contribute to the development of immunoassays to measure SAM, SAH and related molecules. These assays enable the MI to be measured specifically, accurately, easily and quickly without costly equipment. This preliminary study indicates that the Ml could be an effective indicator of general health, except under conditions that may alter the value of the Ml, such as special diets and medications.
\end{abstract}

Keywords: Antibody, Immunoassay, Methylation index, S-Adenosylmethionine, S-Adenosylhomocysteine, Diseases, Biomarker, Competitive ELISA, Conjugates

\section{Background}

$S$-Adenosylmethionine (SAM, SAMe, or AdoMet) is a naturally occurring compound found in all living cells.

\footnotetext{
*Correspondence: sheryl.hao@arthusbio.com

${ }^{1}$ Arthus Biosystems, 2600 Hilltop Dr., Richmond, CA 94806, USA

Full list of author information is available at the end of the article
}

SAM is a critical metabolite derived from adenosine triphosphate (ATP) and methionine (Met) via methionine adenosyltransferase (MAT EC2.5.1.6). SAM is an essential, metabolically pleiotropic molecule that participates in multiple cellular reactions as the precursor for the synthesis of glutathione and the major methyl donor for the methylation of nucleic acids, phospholipids, 
histones, biogenic amines, and proteins. SAM is the key molecule in the Met cycle and plays important roles in transmethylation, transsulfuration and aminopropylation. Methylation processes are the central biochemical basis of the neuropsychiatry of folate and B12 metabolism. The de novo synthesis of Met requires vitamin B12, which is involved directly in the transfer of the methyl group to homocysteine (HCys). Deficiency in either vitamin B12 or folate is considered the cause of low methylation index (MI). Metabolic hypomethylation might be one mechanism related to adverse clinical outcomes in B12-deficient individuals [1]. SAM provides the methyl group during the production of essential biomolecules such as carnitine (fat burner), acetyl-L-carnitine (neuro-nutrient, membrane-transporting agent), phosphocreatine (primary ATP reservoir), epinephrine/ adrenalin (endogenous catecholamine, stress hormone and neurotransmitter), phosphatidylcholine (the most important membrane phospholipid), and melatonin (circadian rhythm modulator). Combined administration of $\mathrm{N}$-acetyl cysteine (an antioxidant and glutathione precursor that protects against Abeta neurotoxicity), acetylL-carnitine (increases ATP levels, protects mitochondria, and buffers Abeta neurotoxicity), and $S$-adenosylmethionine (facilitates glutathione usage and maintains acetylcholine levels) enhances or maintains cognitive function and attenuates or prevents aggression, in mouse models of aging and neurodegeneration. Treatment with this nutraceutical combination can compensate for a lack of dietary folate and vitamin E [2]. Transsulfuration begins with SAH, the residual structure of SAM after donating the methyl group (trans-methylation). Hydrolysis of $\mathrm{SAH}$ yields HCys, which is converted to cystathionine, cysteine, and then glutathione, the hepatocellular antioxidant and life-saving detoxification agent. Aminopropylation is another process that is initiated by SAM through decarboxylation. Decarboxylated SAM is coupled to putrescine to generate spermidine and spermine, which are critical for cell growth, differentiation and DNA and RNA stability. Methylthioadenosine (MTA), the by-product of polyamine synthesis, is a powerful analgesic and anti-inflammatory agent that may be responsible for the clinical benefits observed in the treatment of osteoarthritis, rheumatoid arthritis and fibromyalgia with SAM [3, 4].

Defects in methylation lead to cell dysfunction and accompanying changes in SAM levels. Poor methylation or SAM deficiency has been implicated or related to the development of birth defects [5], cardiovascular disease [6], cancers [7], liver disease [8], and many other diseases [9-14, 18, 20, 21]. SAM levels have been identified as a diagnostic marker for Pneumocystis carinii pneumonia (PCP) in patients with immune-compromised conditions
[15]. SAM has been used clinically for the treatment of liver disease, arthritis [16], and depression [17]. SAM produced cognitive improvement in patients with Alzheimer's disease [19]. Treatment with SAM has been confirmed to be as effective as prescription tricyclic antidepressants [22] and non-steroidal anti-inflammatory drugs (NSAIDS) [3], with efficacy for the treatment of some liver conditions, such as cholestasis in pregnancy and intrahepatic cholestasis associated with liver diseases $[23,24]$. More significantly, SAM is well tolerated, and no serious side effects have been observed. SAM provides rapid relief and is superior to tricyclic antidepressant treatment [25].

A deficiency of the major dietary sources of methyl donors, Met and choline, leads to the formation of liver cancer in rodents [26]. Extra-hepatic tumor formation increased in carcinogen-treated animals fed diets low in methyl donors including Met, choline, and folic acid [27]. Several mechanisms explain the enhancing effects of dietary methyl deprivation on carcinogenesis [28], of which the most accepted is that dietary methyl deficiency results in abnormal DNA methylation [29]. A critical metabolite in this hypothesis is SAM, the sole methyl donor in the body. Studies have linked deficiencies in folic acid, vitamin B12, and Met with an increased risk of cancer in various organs [30]. The question thus arises whether such deficiencies exert their activities through diminished availability of SAM. Studies have also demonstrated the utility of determining erythrocyte SAM and $\mathrm{SAH}$ and of plasma HCys in assessing disease status [31].

Due to the importance of SAM and SAH, an easy and reliable method is needed to measure their concentrations in a biological sample. A classic method for measuring SAM and SAH in rat liver utilizes the tripolyphosphatase activity associated with SAM synthetase in rat liver [32]. Tripolyphosphatase activity is stimulated by low concentrations of SAM [33]. The reported sensitivity of this method is $0.1 \mathrm{nmol}$ of SAM in an assay volume of $0.1 \mathrm{~mL}$ (i.e., $10^{-6} \mathrm{M}$ ). The samples are lyophilized, homogenized in acid, and centrifuged. The supernatant is then passed through Dowex 1 to remove endogenous inorganic phosphate and other potential interferons in the tissue. Great care is needed to avoid inorganic phosphate contamination from all reagents, including the enzyme preparation and glassware. The disadvantages of this assay are a clear lack of specificity, low sensitivity $(1 \mu \mathrm{M})$, and difficulties related to controls and comparisons among assays in different laboratories. Another common method for measuring SAM in tissues or biological fluids is HPLC or electrophoresis after sample preparation, which normally comprises protein precipitation and/or extraction [34]. Post-column detection may include derivatization followed by measurement 
by absorption, fluorescence, or electrochemical changes and, more recently, by LC-MS/MS [35]. These methods are laborious, time-consuming and require expensive equipment. LC-MS/MS does not consider the biological relevance of the detected metabolites. Therefore, the use of LC-MS/MS to measure SAM and SAH may not be accurate or complete from a biological perspective. Chemical methods can only detect the free form of SAM or SAH at the time of sample collection and exclude any SAM or SAH associated with other biomolecules. The inability of LC-MS/MS to detect SAM molecules that fall within the specific molecular weight range defined by LC-MS/MS in a sample does not indicate that SAM has been completely degraded, lost or is not functional. Furthermore, the SAM standard used to train LC-MS/MS is not identical to SAM from living cells. However, for a technology such as LC-MS/MS, a molecule identical to the molecule of interest is required as the training standard. Recent studies have suggested that GC-MS and LC-MS analytical methods may not accurately measure metabolites due to changes caused by lengthy and high-temperature manipulation processes during sample extraction, preprocessing and measurement [36].

SAM is an intrinsically unstable molecule, and its optical density maximum of $258-260 \mathrm{~nm}$ is not unique. Thus, the determination of the concentration of SAM in various biological fluids and tissues is a challenging task. A simple, convenient method that does not require costly instrumentation is clearly desirable for determining the biological concentration of SAM and monitoring changes in SAM levels in body fluids, tissues and organelles. The MI is defined as the ratio of the concentration of SAM to the concentration of SAH. Given the important roles of SAM and SAH in various pathological processes, it is desirable to conveniently measure the levels of SAM and SAH using methods that can be performed in typical research and clinical laboratories. The availability of specific antibodies against SAM and SAH has enabled the development of various forms of immunoassays to satisfy different needs. In this study, the generation and characterization of anti-SAM and anti-SAH antibodies as well as their applications are described. The usefulness of blood SAM and MI as markers for evaluating the roles of SAM in the onset and development of human diseases was also evaluated. This investigation included the determination of SAM, SAH, and MI in blood samples collected from normal and diseased subjects.

\section{Methods}

\section{The hapten used to generate anti-SAM antibodies}

Many SAM analogs were synthesized as shown in US patent No. 8,344,115 and evaluated to identify the best analog to generate the best anti-SAM antibodies. One of the most promising analogs, $5^{\prime}-N$-methyl, $5^{\prime}-N$-butyryl- $5^{\prime}$ deoxyadenosine, or $5^{\prime}$-((3-carboxypropyl)methylamino)$5^{\prime}$-deoxy-adenosine, abbreviated as aza-deamino-SAM or shortened as aza-SAM, was employed to immunize Balb/c mice. All asymmetric carbons in aza-SAM maintained their chirality.

\section{Preparation of KLH-aza-SAM}

To a flask containing $15 \mathrm{mg}$ of aza-SAM that was vacuum-dried overnight, appropriate amounts (proportional to aza-SAM) of DCC (N,N'-dicyclohexylcarbodiimide), NHS ( $N$-hydroxysuccinimide) and KLH (keyhole limpet hemocyanin) were added. Approximately $1.5 \mathrm{~mL}$ of dry DMF (dimethylformamide) was then added to the flask. The solution was stirred at room temperature. Formation of the NHS ester was confirmed by thin layer chromatography. The final volume after dialysis was $29.5 \mathrm{~mL}$ with a concentration of $0.6 \mathrm{mg} / \mathrm{mL}$.

\section{Preparation of PLL-aza-SAM (poly-L-lysine-conjugated aza-SAM)}

A $4.72-\mathrm{mg}$ quantity of aza-SAM was dissolved in $1 \mathrm{~mL}$ of DMF with $6.5 \mathrm{mg}$ EDC (1-ethyl-3-(3-dimethylaminopropyl) carbodiimide. Next, $\mathrm{HCl}$ and $4 \mathrm{mg}$ of NHS were added, followed by stirring at room temperature in the dark overnight. Then, $1.5 \mathrm{mg}$ of PLL was dissolved in $1 \mathrm{~mL}$ of $10 \mathrm{mM}$ PBS pH 8.2. Aza-SAM was then added slowly to the PLL solution, and the mixture was incubated overnight in the dark. The reaction mixture was dialyzed for $48 \mathrm{~h}$ against $10 \mathrm{mM}$ PBS, $\mathrm{pH}$ 7.3.

\section{Preparation of BSA-SAH}

A 3.8-mg quantity of SAH (Sigma) was dissolved in $1.5 \mathrm{~mL}$ of PBS. Then, $10 \mathrm{mg}$ of EDC $\mathrm{HCl}$ (Sigma) and $4.5 \mathrm{mg}$ of NHS were added, and the mixture was stirred at room temperature for $24 \mathrm{~h}$. We then dissolved $12.9 \mathrm{mg}$ of BSA in PBS. The SAH was added to the BSA solution, and the mixture was incubated at $4{ }^{\circ} \mathrm{C}$ in the dark overnight.

\section{Preparation of HRP-conjugated antibodies}

To develop a more efficient ELISA, HRP (horseradish peroxidase, Sigma) was directly conjugated to mouse anti-SAM and mouse anti-SAH antibodies. Five milligrams of HRP (dissolved in deionized water at $10 \mathrm{mg} /$ $\mathrm{mL}$ ) was added to $0.5 \mathrm{~mL}$ of freshly prepared $0.06 \mathrm{M}$ sodium periodate and incubated at $4{ }^{\circ} \mathrm{C}$ for $30 \mathrm{~min}$. Approximately $5 \mathrm{mg}$ of antibody was added to the HRP solution and dialyzed overnight against $50 \mathrm{mM}$ carbonate buffer, $\mathrm{pH}$ 9.6. Approximately $2 \mathrm{mg}$ of sodium borohydride was added to the reaction mixture and incubated in the dark at $4{ }^{\circ} \mathrm{C}$ for $2 \mathrm{~h}$ with shaking once every $30 \mathrm{~min}$. The sample was then dialyzed against $0.01 \mathrm{M}$ PBS, $\mathrm{pH}$ 7.2 , for at least $18 \mathrm{~h}$. 


\section{Procedures for generating monoclonal antibodies against SAM and SAH}

Mouse monoclonal antibodies were produced based on procedures developed in a previous work [37]. Immunization was performed via subcutaneous injection of $0.1 \mathrm{mg}$ of antigen at multiple sites into Balb/c mice. The initial injection consisted of a 1:1 mixture of complete Freund's adjuvant and aza-SAM-KLH or SAH-BSA conjugate solutions in PBS upon emulsification. The subsequent 3 injections were similar except for the use of incomplete Freund's adjuvant. Blood was collected from each immunized mouse at 1-2 weeks. The obtained antisera were then evaluated to determine the immune response and the antibody titer. Mice with satisfactory titers were primed via intravenous injection with immunogen three days prior to its sacrifice. The spleens of the mice were harvested and homogenized. The spleen cells were then fused with myeloma SP2/0 cells, and the fused cell suspension was plated out in 96-well microtiter plates. Hybridomas were grown in RPMI 1640 medium enriched with 18\% fetal bovine serum, HAT and HT supplements and then screened. Clones that were positive for SAM or SAH were selected for further studies, including cross-reactivity tests. After the clones were obtained, the cells were injected into mice for ascite production. The antibody was then purified from the ascites using a protein A affinity column.

\section{Methionine adenosyltransferase (MAT)-catalyzed SAM biosynthesis}

Solutions of $1 \mathrm{mM}$ ATP and L-Met (Sigma) were prepared in $100 \mathrm{mM}$ Tris, $100 \mathrm{mM} \mathrm{KCl,} 20 \mathrm{mM} \mathrm{MgSO}_{4}$, and $1 \%$ ProClin, pH 7.42. Recombinant E. coli MAT was added to the above substrates at a concentration of $0.6 \mathrm{mg} / \mathrm{mL}$ or $1 \mathrm{mg} / \mathrm{mL}$, respectively. The reaction mixture was analyzed in duplicate using the SAM cELISA described in this section. The synthesized SAM was measured every $10 \mathrm{~min}$ after incubation at $37^{\circ} \mathrm{C}$ for $20-80 \mathrm{~min}$.

\section{Blood sample collection}

Informed consent for sample collection and publication of clinical data was obtained from the participants. Sera were obtained from 81 normal volunteers, 310 plasma samples from the Changsha Blood Center and sera from 505 patients. For the plasma samples, peripheral venous blood was collected in tubes with EDTA and mixed well. The tubes were immediately cooled to $4{ }^{\circ} \mathrm{C}$ and centrifuged at $2000 \mathrm{~g}$ or higher for $15 \mathrm{~min}$ within $30 \mathrm{~min}$ after blood collection to obtain plasma. The plasma was either used for the measurements or frozen at $-20{ }^{\circ} \mathrm{C}$ for future use. Serum samples were collected in serum separating tubes and placed in the refrigerator for approximately $2 \mathrm{~h}$ until blood coagulation occurred. The remaining steps were similar to those used for plasma collection. Plasma from the blood center was stored in the refrigerator for 1-7 h before centrifugation and freezing.

The Supplemental Data (Additional file 1) provides details regarding disease information. Patient samples were collected from clinical laboratories with no further information about the patient and disease conditions, status and treatments. Statistical analyses were performed using R by Dr. Huaitian Liu (National Cancer Institute, National Institute of Health, Rockville, MD) and Sydney Wong (University of California, Berkeley, CA).

\section{Competitive ELISA (cELISA)}

To quantify plasma SAM and SAH levels, direct cELISA was developed by immobilizing antigens to a solid plate first, followed by the addition of SAM or SAH and HRPlabeled anti-SAM or anti-SAH antibodies. Antigens from a sample or standards competed with the corresponding fixed amount of immobilized antigens for binding to specific HRP-labeled antibodies. The final HRP substrate absorption values at $450 \mathrm{nM}$ were inversely proportional to the amount of detected antigen, i.e., the higher the OD450 value, the lower the level of SAM or SAH in a sample. The wells of a 96-well ELISA plate (Corning high-affinity strips for ELISA) were coated with $0.05 \mu \mathrm{g} /$ $\mathrm{mL}$ PLL-aza-SAM or $0.5 \mu \mathrm{g} / \mathrm{mL}$ BSA-SAH at $4{ }^{\circ} \mathrm{C}$ overnight. A series of SAM or SAH standards (aza-SAM from 0 to $960 \mathrm{nM}$ and SAH-Na from 0 to $100 \mathrm{nM}$ ) and samples were added, followed by a 1:30,000 dilution of HRP-antiSAM to a final volume of $100 \mu \mathrm{l}$. The plate was sealed and incubated at $37^{\circ} \mathrm{C}$ for $60 \mathrm{~min}$. The plate was then washed 3 times with PBST (10 mM PB, $150 \mathrm{mM} \mathrm{NaCl}, \mathrm{pH}$ 7.4, $0.1 \%$ Tween 20). TMB (3,3',5,5'-tetramethylbenzidine) was added to the wells (InnoReagents), and the plate was sealed and incubated for $15 \mathrm{~min}$ at $37{ }^{\circ} \mathrm{C}$. The reaction was then stopped, and the OD450 values were read using a Multiskan FC reader (Thermo Fisher). The standards were generated using heat-inactivated pooled normal human plasma to minimize the matrix effect.

\section{Other materials}

All analogs used in the cross-reactivity tests were from Sigma.

\section{Results and discussion Antibodies and immunoassays Characterization of the anti-SAM monoclonal antibodies 118-6 and 84-3}

A good and useful antibody should have high specificity, sensitivity and affinity. The best way to demonstrate that the newly developed anti-SAM antibody specifically binds to SAM is to confirm that the anti-SAM antibody can bind to in vitro-synthesized SAM identical to the SAM synthesized in living cells. Figure 1 
shows that the amount of SAM synthesized increased with a longer reaction time but reached a maximum after $60 \mathrm{~min}$. This result indicates that the product of Met catalysis of ATP and Met was able to competitively bind the anti-SAM antibody. Dosage-dependent competition was detected as the sample was added to the cELISA system; SAM from the sample competed with the coated SAM hapten to bind the HRP-conjugated antibody 118-6. The sample consisted of Met, ATP and MAT in $100 \mathrm{mM}$ Tris, $100 \mathrm{mM} \mathrm{KCl,} 50 \mathrm{mM} \mathrm{MgCl}_{2}$, $\mathrm{pH} 7.42$, and $1 \%$ ProClin. The results indicated that the developed anti-SAM all specifically bind to physiologically produced SAM. The system permits simultaneous MAT-catalyzed SAM synthesis and SAM immunoassay, thus ensuring the accuracy of the results because SAM is unstable and termination of the MAT catalytic reaction at a precise time point is difficult. The use of cELISA to directly measure SAM in this scenario has even more important advantages for two reasons: (a) following synthesis, SAM remains associated with MAT for a period of time before release, and the traditional HPLC and MS methods for measuring SAM are unable to measure SAM in the MAT-SAM complex; (b) the preprocessing steps for HPLC and MS inevitably cause some SAM decomposition, leading to inaccurate results. The results in Fig. 2 indicate not only that the naturally produced SAM can compete in a dose-dependent manner with the SAM or aza-SAM coated onto the microtiter plates in terms of anti-SAM

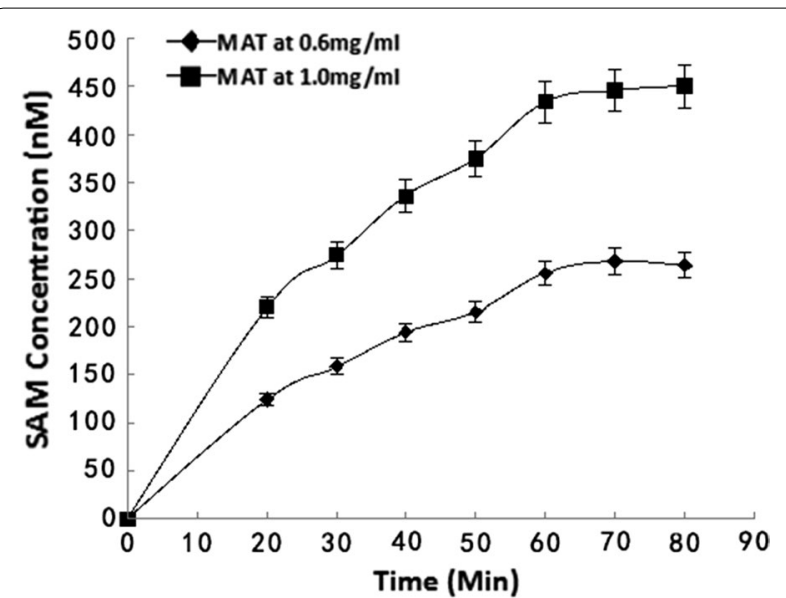

Fig. 1 Detection of SAM synthesized from Met and ATP as substrates by the MAT-catalyzed reaction over time. The cELISA was used to measure SAM. The samples for the cELISA were the product of the following biochemical reaction. MAT was added to a maximum of $2 \mathrm{mM}$ Met and ATP in the buffer described in the Methods at $37^{\circ} \mathrm{C}$. The biochemical reaction and ELISA were performed simultaneously and then stopped at 20,30, 40, 50, 60, 70 and 80 min after the reaction. Different amounts of MAT and buffers were tested antibody binding but also that the method is a quick, easy and accurate way to measure the enzymatic activity of MAT. Thus, anti-SAM antibodies can be used to accurately measure MAT activity.

Cross-reactivity with SAM analogs was tested using up to 100-fold higher dosages of analogs than that of SAM antigen with the established cELISA method. Figure 2 shows a cELISA using the anti-SAM monoclonal antibody $118-6$. In this assay, $0.1 \mu \mathrm{g} / \mathrm{mL}$ PLL-aza-SAM was used to coat a 96-well plate. Serial dilutions of Aza-SAM, $\mathrm{SAH}$, adenosine, L-Met, ADP (adenosine diphosphate), ATP, MTA and 1:35,000 of 118-6 antibody were added. HRP-conjugated goat anti-mouse IgG antibody and TMB substrate were used to develop the results. The crossreactivity of antibody 84-3 was similar to that of 118-6. At concentrations exceeding $10 \mu \mathrm{M}$ Met, SAH, MTA, adenosine, ADP, and ATP, competition for the coated antigen (PLL-aza-SAM) with the HRP-antibody did not occur (data not shown). No competitive inhibition of the HRP signal was observed using these analogs, whereas inhibition was clearly evident when SAM was added at a much lower dosage than the analogs. These data indicate that the cross-reactivity of all analogs was $<1 \%$.

When the antibodies were adjusted to $1 \mathrm{mg} / \mathrm{mL}$ in an indirect ELISA assay, the titer of the anti-SAM monoclonal antibodies ranged from 1:10,000 to 1:100,000 depending on the criteria and conditions used.

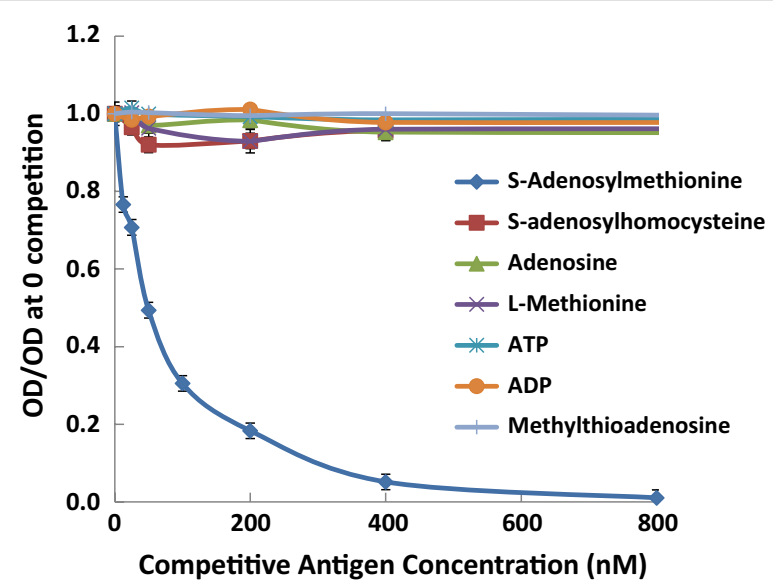

Fig. 2 Cross-reactivity of the mouse anti-SAM monoclonal antibody 118-6 with SAM analogs. Each well of a 96-well plate was coated with $0.1 \mu \mathrm{g} / \mathrm{mL}$ PLL-aza-SAM, and serial dilutions of the SAM standard azaSAM, S-adenosylhomocysteine (SAH), adenosine (Ade), L-methionine (Met), methylthioadenosine (MTA), adenosine diphosphate (ADP), and adenosine triphosphate (ATP) and 1:35,000 antibody were added. HRP-conjugated goat anti-mouse IgG antibody and substrate TMB were then added. The $y$-axis shows the OD450 of each well in relation to the wells without antigen competition. The $x$-axis shows the concentration of SAM. A lower value on the $y$-axis indicates greater competition 
To demonstrate the ease and affinity of antigen and antibody binding, ELISA assays were performed using different amounts of coated antigens. For the anti-SAM clone 118-6, when antigen was coated at a higher concentration of $0.2 \mu \mathrm{g} / \mathrm{mL}$, half the maximum $\mathrm{OD}$ was obtained at a dilution of 1:54,800. The corresponding antibody concentration was $(\mathrm{Ab})=\left(1 \mathrm{mg} \mathrm{mL}^{-1} / 160,000\right.$ $\left.\mathrm{g} \mathrm{mol}^{-1}\right) / 54,800=1.14 \times 10^{-10} \mathrm{M}$, where 160,000 is the molecular weight of the antibody. When the coating antigen concentration was less than $0.1 \mu \mathrm{g} / \mathrm{mL}$, half the maximum OD was observed at 1:44,300. The corresponding antibody concentration was $(\mathrm{Ab})_{\mathrm{t}}=\left(1 \mathrm{mg} \mathrm{mL}^{-1 / 160,000}\right.$ $\left.\mathrm{g} \mathrm{mol}^{-1}\right) / 44,300=1.41 \times 10^{-10} \mathrm{M}$, where $\mathrm{n}=0.2 / 0.1(\mu \mathrm{g} /$ $\mathrm{mL})=2, \mathrm{Ka}=(\mathrm{n}-1) / 2^{*}\left(\mathrm{n}(\mathrm{Ab})-(\mathrm{Ab})_{\mathrm{t}}\right)=5.75 \times 10$ ${ }^{9} \mathrm{~L} / \mathrm{mol}=1.74 \times 10^{-10} \mathrm{M}$. For clone 84-3, when the coating antigen was $0.1 \mu \mathrm{g} / \mathrm{mL}$, half the maximum OD was observed at approximately 1:13,0000. When the coating antigen was $0.05 \mu \mathrm{g} / \mathrm{mL}$, half the maximum OD was detected when 84-3 was diluted at approximately 1:70,000. Using the same method as above, $\mathrm{Ka}=(\mathrm{n}-1) /$ $2^{*}\left(\mathrm{n}[\mathrm{Ab}]-[\mathrm{Ab}]_{\mathrm{t}}\right)=7.29 \times 10^{10} \mathrm{~L} / \mathrm{mol}=1.37 \times 10^{-11} \mathrm{M}$.

Tables 1, 2 shows the results of a SAM cELISA using three different coating amounts of PLL-aza-SAM when mouse anti-SAM antibody 84-3 was used at a dilution of 1:35,000 and from one coating plate when antibody 118-6 was tested in indirect cELISA assays. Different amounts of coating antigen, antibody, and buffer provide slightly different minimum detection limits. The data in Table 1 demonstrate that the minimum detection limits were between 1.6 and $3 \mathrm{nM}$ when antibody $84-3$ was used, depending on the coating antigens (see Table 1; Fig. 3a), and $7.8 \mathrm{nM}$ when antibody 118-6 was used at a dilution of 1:32,000 (see Table 2; Fig. 3b). These values were estimated from the corresponding concentrations calculated from the standard curve equation given the OD450, that is, the average of the OD450 minus twice the standard deviation (SD) of the blank wells (without antigen). When the same amount of coating antigen $(0.1 \mu \mathrm{g} / \mathrm{mL})$ was used, antibody 84-3 exhibited higher sensitivity than antibody
Table 2 Sensitivity of mouse anti-SAM antibody 118-6

\begin{tabular}{llllll}
\hline SAM standard (nM) & OD450 & OD450 & OD450 & Mean & SD \\
\hline Blank & 0.0556 & 0.0808 & 0.0616 & 0.0660 & 0.0131 \\
0 & 1.2189 & 1.2831 & 1.3030 & 1.2683 & 0.0439 \\
6.3 & 1.110 & 1.0648 & 0.9757 & 1.0502 & 0.0683 \\
12.5 & 0.885 & 0.8004 & 0.8737 & 0.8530 & 0.0459 \\
25 & 0.6252 & 0.6435 & 0.6108 & 0.6265 & 0.0164 \\
50 & 0.3838 & 0.3995 & 0.3782 & 0.3872 & 0.0110 \\
Sensitivity $^{\text {a }}$ & $2.6 \mathrm{nM}$ & & & &
\end{tabular}

a Sensitivity was estimated by the corresponding concentration calculated from standard curve given the OD 450 (=OD450 at zero antigen $-2 \times$ standard deviation of blank wells). ELISA was performed in triplicates. PLL-aza-SAM was coated at $0.1 \mu \mathrm{g} / \mathrm{mL}$ and the $118-6$ used at 1:32,000

118-6, consistent with the greater binding affinity of 84-3 compared with 118-6. The single-digit nM sensitivity indicates great potential in applications evaluating these critical metabolites under various conditions. Because SAM levels decreased under pathological conditions, it will be very important to obtain antibodies that are sufficiently sensitive to measure the low levels of SAM in samples.

Characterization of the anti-SAH monoclonal antibody 301-1 The antibody specificity was evaluated by examining the cross-reactivity of 301-1 with SAH analogs. Figure 4 shows a cELISA using 301-1. A BSA-SAH concentration of $0.5 \mu \mathrm{g} / \mathrm{mL}$ was coated in each well of a 96-well plate. Serial dilutions of the SAH standard (SAHNa), S-adenosylmethionine (SAM4: Sigma Cat\# A2408, SAM1: aza-SAM), HCys, L-cysteine (L-Cys), adenosine (Ade), glutathione (GST), L-cystathionine (L-CTT), MTA, ADP, ATP and properly diluted 301-1 were added. The crossreactivity was approximately $1.5 \%$ with SAM, approximately $5 \%$ with MTA, and $<1 \%$ with all other analogs. The relatively higher cross-reactivity with SAM and MTA $(<5 \%)$ is not a concern because the physiological levels of SAM and MTA are much lower than $1 \mu \mathrm{M}$, a level at which no cross-reactivity with the antibody was observed.

Table 1 OD450 measured using different amounts of coating antigens with antibody 84-3

\begin{tabular}{|c|c|c|c|c|c|c|c|c|c|}
\hline \multirow{2}{*}{$\begin{array}{l}\text { SAM standard (nM) } \\
\text { Blank }\end{array}$} & \multicolumn{3}{|c|}{$0.2 \mu \mathrm{g} / \mathrm{mL}$} & \multicolumn{3}{|c|}{ PLL-aza-SAM $0.15 \mu \mathrm{g} / \mathrm{mL}$} & \multicolumn{3}{|c|}{$0.1 \mu \mathrm{g} / \mathrm{mL}$} \\
\hline & 0.0498 & 0.056 & 0.0522 & 0.0476 & 0.0471 & 0.0482 & 0.0754 & 0.0515 & 0.0476 \\
\hline 0 & 1.4709 & 1.4344 & 1.4072 & 1.215 & 1.2484 & 1.2651 & 1.0844 & 1.1231 & 1.0633 \\
\hline 6.3 & 1.365 & 1.3257 & 1.2673 & 1.0789 & 1.0734 & 1.0842 & 0.879 & 0.9122 & 0.8995 \\
\hline 25 & 1.1769 & 1.1498 & 1.1015 & 0.8231 & 0.844 & 0.8334 & 0.6209 & 0.6561 & 0.6679 \\
\hline 50 & 1.0230 & 0.9856 & 0.9577 & 0.6428 & 0.6362 & 0.6005 & 0.4517 & 0.4555 & 0.5187 \\
\hline 100 & 0.7687 & 0.7532 & 0.7292 & 0.4292 & 0.4203 & 0.4427 & 0.3036 & 0.3103 & 0.3071 \\
\hline Sensitivity ${ }^{a}$ & \multicolumn{3}{|l|}{$3.0 \mathrm{nM}$} & \multicolumn{3}{|l|}{$1.7 \mathrm{nM}$} & \multicolumn{3}{|l|}{$1.6 \mathrm{nM}$} \\
\hline
\end{tabular}

a Sensitivity was estimated by the corresponding concentration calculated from standard curve equation given the OD450 (=OD450 at zero antigen $-2 \times$ standard deviation of blank wells). ELISA was performed in triplicates. Mouse anti-SAM antibody 84-3 was used at 1:35,000 


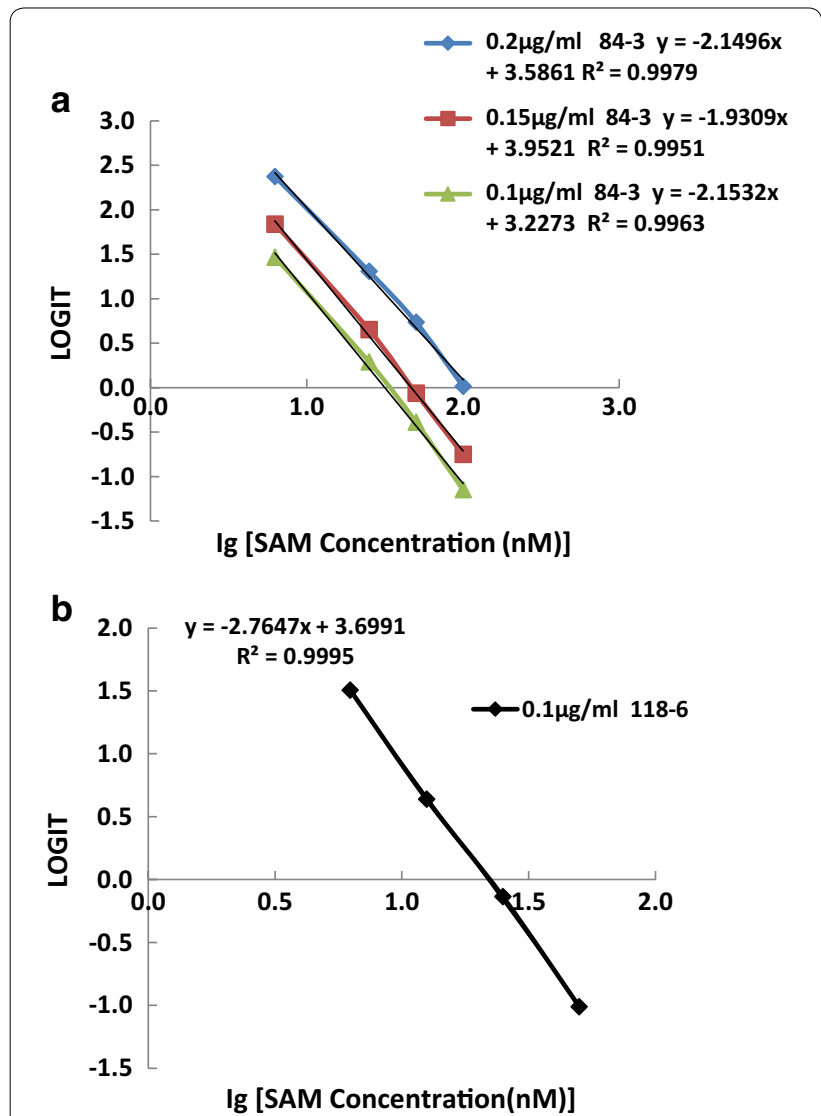

Fig. 3 Standard curves for the mouse monoclonal antibody against SAM in the sensitivity tests. a Using antibody $84-3$ at $1: 35,000$ with different amounts of coating antigens $(0.1,0.15$, and $0.2 \mu \mathrm{g} / \mathrm{mL})$ in an indirect CELISA. b Using antibody $118-6$ at 1:32,000 with coating antigen at $0.1 \mu \mathrm{g} / \mathrm{mL}$ in an indirect cELISA. The $x$-axis shows the values of the base 10 logarithm of the standard concentrations. The $y$-axis is expressed as LOGIT, which is defined as $\operatorname{Ln}\left(A / A_{50} /\left(1-A / A_{50}\right)\right)$, where $A$ is the OD450 value of the standard and $A_{s 0}$ is the OD450 value of the blank (without antigen). The equation for each standard curve is shown

Using the same method described above for affinity, when the coating antigen was $1 \mu \mathrm{g} / \mathrm{mL}$, half the maximum OD was observed at a dilution of 1:1900. When the coating antigen was $0.5 \mu \mathrm{g} / \mathrm{mL}$, half of the maximum OD was observed at approximately 1:1100. Thus, $\mathrm{Ka}=(\mathrm{n}-1) / 2^{*}$ $\left(\mathrm{n}[\mathrm{Ab}]-[\mathrm{Ab}]_{\mathrm{t}}\right)=2.79 \times 10^{8} \mathrm{~L} / \mathrm{mol}=3.6 \times 10^{-9} \mathrm{M}$. The titer of 301-1 was in the range of 1:4000-8000 when the antibodies were adjusted to a concentration of $1 \mathrm{mg} / \mathrm{mL}$ in an indirect ELISA assay.

Table 3 shows the cELISA results for $0.5 \mu \mathrm{g} / \mathrm{mL}$ BSASAH coated onto a microtiter plate with mouse anti-301-1 at a dilution of 1:1000. Different amounts of coating antigen, antibody, and incubating buffer may provide slightly different minimum detection limits. The same method described above was used to calculate the minimum detection limit, which was approximately $15.6 \mathrm{nM}$.

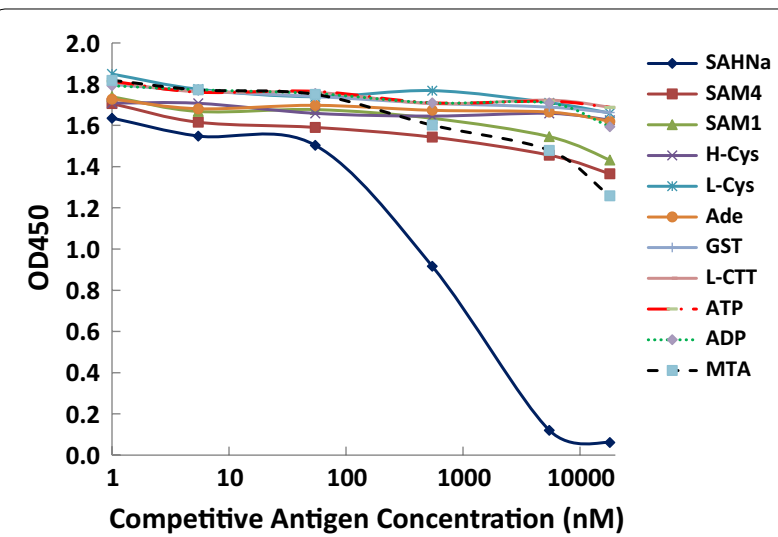

Fig. 4 Cross-reactivity of the mouse anti-S-adenosylhomocysteine monoclonal antibody 301-1 with SAH analogs. Each well of a 96-well plate was coated with $0.5 \mathrm{\mu g} / \mathrm{mL}$ BSA-SAH. Serial dilutions of SAH standard (SAH sodium, SAH-Na), S-adenosylmethionine (SAM4: from Sigma-Aldrich Cat\# A2408, SAM1: aza-SAM), homocysteine (H-Cys), L-cysteine (L-Cys), adenosine (Ade), glutathione (GST), L-cystathionine (L-CTT), methylthioadenosine (MTA), ADP (adenosine diphosphate), ATP (adenosine triphosphate) and properly diluted 301-1 were added. HRP-conjugated goat anti-mouse lgG antibody and TMB substrate were added to develop the color, and the OD450 was measured. The $y$-axis shows the OD450 for each test. The $x$-axis shows the concentration of SAH. A lower OD450 value indicates greater competition

Table 3 SAH standard curve and sensitivity of antibody 301-1

\begin{tabular}{|c|c|c|c|c|c|}
\hline SAH (nM) & OD450 & OD450 & OD450 & Mean & SD \\
\hline 250 & 0.4116 & 0.4426 & 0.442 & 0.4321 & 0.0177 \\
\hline 125 & 0.5421 & 0.6358 & 0.5372 & 0.5717 & 0.0555 \\
\hline 62.5 & 0.6055 & 0.7115 & 0.6444 & 0.6538 & 0.0536 \\
\hline 31.3 & 0.7285 & 0.8199 & 0.7545 & 0.7676 & 0.0471 \\
\hline 15.6 & 0.8045 & 0.8273 & 0.7975 & 0.8098 & 0.0156 \\
\hline 7.8 & 0.7602 & 0.8113 & 0.7708 & 0.7808 & 0.0270 \\
\hline 3.9 & 0.7722 & 0.9144 & 0.7786 & 0.8217 & 0.0803 \\
\hline 0 & 0.8770 & 0.8992 & 0.8329 & 0.8697 & 0.0337 \\
\hline Sensitivity ${ }^{a}$ & $\sim 15.6 \mathrm{nM}$ & & & & \\
\hline
\end{tabular}

a Sensitivity was estimated by the corresponding concentration calculated from standard curve given the OD 450 (=OD450 at zero antigen $-2 \times$ standard deviation of blank wells). ELISA was performed in triplicates. BSA-SAH was coated at $0.5 \mu \mathrm{g} / \mathrm{mL}$ and mouse anti-SAH antibody $301-1$ was used at 1:2000

\section{CELISA}

The standard curves for cELISA of SAM and SAH are shown in Figs. $5 \mathrm{a}, \mathrm{b}$, respectively. LOGIT $=\mathrm{Ln}\left(\mathrm{A} / \mathrm{A}_{\mathrm{SO}} /\right.$ $\left.\left(1-\mathrm{A} / \mathrm{A}_{\mathrm{SO}}\right)\right)$, where $\mathrm{A}$ is the OD450 value of a sample or the standard and $\mathrm{A}_{\mathrm{S} 0}$ is the OD450 value of the control (without antigen). A negative LOGIT value indicates that $\mathrm{A} / \mathrm{A}_{\mathrm{S} 0}$ is less than $50 \%$ and the inhibition rate $\left(1-\mathrm{A} / \mathrm{A}_{\mathrm{S} 0}\right)$ is greater than $50 \%$. As shown in Fig. $5 \mathrm{a}$, the standard curves were very similar when different dilutions of HRP-anti-SAM antibody 118-6 of between 


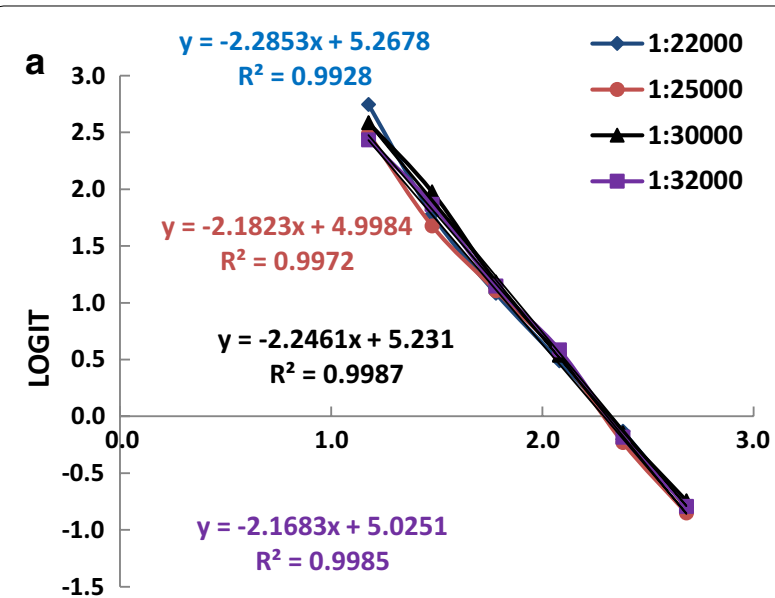

Ig[Concentration of SAM Standard (nM)]

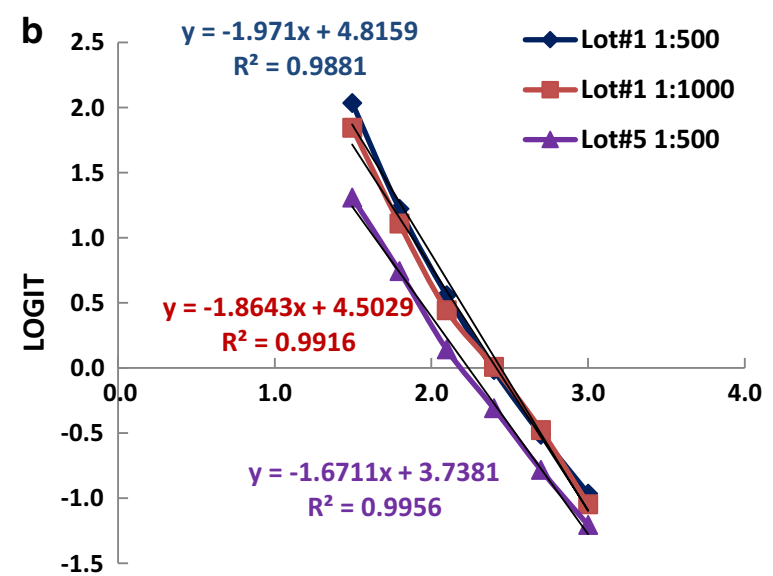

Ig[Concentration of SAH Standard (nM)]

Fig. 5 Standard curves for the quantification of SAM (a) and SAH (b) by the direct CELISA. The $x$-axis shows the values of the base 10 logarithm of the concentrations of the standards. The $y$-axis is expressed as the LOGIT, which is defined as $\operatorname{Ln}\left(A / A_{S 0} /\left(1-A / A_{S 0}\right)\right)$, where $A$ is the OD450 value of the standard and $A_{S 0}$ is the OD450 value of the control (without antigen). a HRP-118-6 was diluted 1:22,000, 1:25,000, 1:30,000 and 1:32,000. The standard curve equations for the 3 different diluted tests are shown in the figure. b Different lots of HRP-301-1 and different dilutions were used. The standard curve equations for the 3 tests are shown

1:22,000 and 1:32,000 were used. As shown in Fig. 5b, different batches of HRP-anti-SAH antibody 301-3 provided slightly different competitive inhibition results, with Lot\# 5 exhibiting greater inhibition. Competitive inhibition results in reduced OD450 readings from TMB substrates due to the addition of a high dosage of free SAM or aza-SAM, allowing less coated PLL-aza-SAM to bind to the HRP-anti-SAM antibody. After washing the microtiter plate, less HRP-anti-SAM remained on the plate, and thus the weaker OD450 was equivalent to an inhibitory effect. As shown in Fig. 5a, a significant portion of the SAM standard curve was within the negative portion of the $y$-axis (LOGIT). A negative LOGIT indicates competitive inhibition exceeding $50 \%$. For the SAH standard curve, as represented in Fig. 5b, a small portion of the SAH standard curve was within the negative LOGIT. Therefore, the inhibition rate is much higher in SAM cELISA than in SAH cELISA, which is partly determined by differences in the affinity of the anti-SAM and anti-SAH antibodies.

SAH is normally low in humans, and thus the ability to measure low levels of SAH is essential. The sensitivities of the anti-SAM and anti-SAH antibodies reported herein are the best to date. Using direct cELISA, the minimum detection limit was approximately $2 \mathrm{nM}$ for SAM and $15 \mathrm{nM}$ for SAH. Other more sensitive immunological technologies can be developed to further reduce the minimum detection limit, increase the range of detection, or improve the assays via faster, easier and higher throughput and better quality control and precision. Sensitivity is essential for most IVD (in vitro diagnosis) applications.

SAH is metabolically linked to SAM, and the structure of SAH contains one less carbon (a methyl group) than SAM. The co-existence and structural similarity of SAM and SAH present a great challenge in the development of a method for the specific determination of the concentration of either molecule in a biological sample. The unstable nature of SAM further complicates its determination. As the immediate precursor of HCys produced in the body, SAH has recently been suggested to be a more sensitive indicator of the risk of vascular diseases than plasma HCys [38]. The total plasma concentration of SAH is normally much lower than that of HCys. As with SAM, SAH has no distinct absorption characteristics, hindering its detection in serum or plasma. Because $\mathrm{SAH}$ is the product of all methylation reactions involving SAM as a methyl donor, an increased concentration of $\mathrm{SAH}$ in tissues is frequently accompanied by a decreased concentration of SAM. Therefore, the ratio of SAM to $\mathrm{SAH}$ is considered a more sensitive indicator than the concentration of either SAM or SAH alone, particularly when their changes are subtle during the early stages of dysfunction or under abnormal conditions. In this work, we established convenient immunoassays to measure the MI quickly without costly instrumentation.

\section{The level of SAM varies with age and gender Normal distribution of SAM and SAH levels in normal serum or plasma samples}

Using the statistical methods in the $\mathrm{R}$ program, the distributions of SAM and SAH values among normal and diseased samples were calculated. Figure $6 \mathrm{a}$ shows the SAM and SAH values and distributions 
from 81 normal serum samples. The average and SD was $386 \mathrm{nM} \pm 216.2$ for SAM, $256.9 \pm 150.7$ for $\mathrm{SAH}$, and $2.2 \pm 1.9$ for the MI. Figure $6 \mathrm{~b}$ shows the SAM and SAH values and distributions from 291 serum samples. The results suggest normal distributions of SAM and $\mathrm{SAH}$ values from the subjects investigated. Therefore, Student's $t$ test was employed for statistical analysis.
The distribution graph of diseased SAM levels also indicated that a significant number of patients had SAM values less than $300 \mathrm{nM}$. In contrast to the graph of the diseased SAH cases, the mean value of SAM did not represent the values of the majority of the samples, partially implying that many factors affect the SAM level.

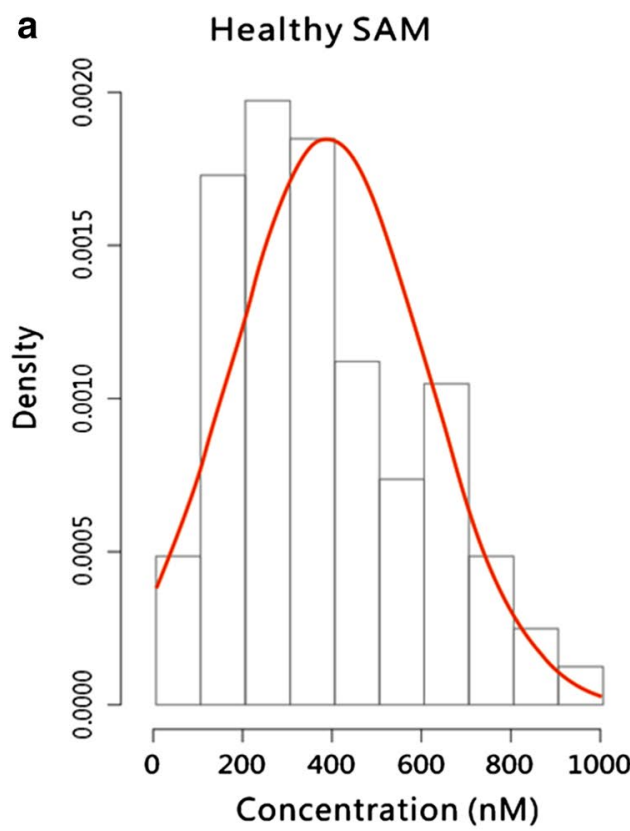

b

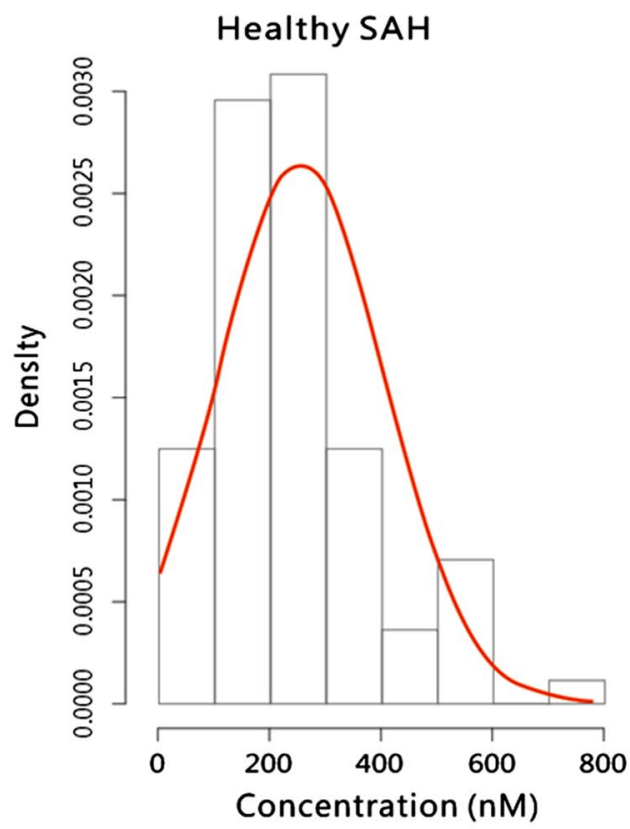

SAM in Diseases
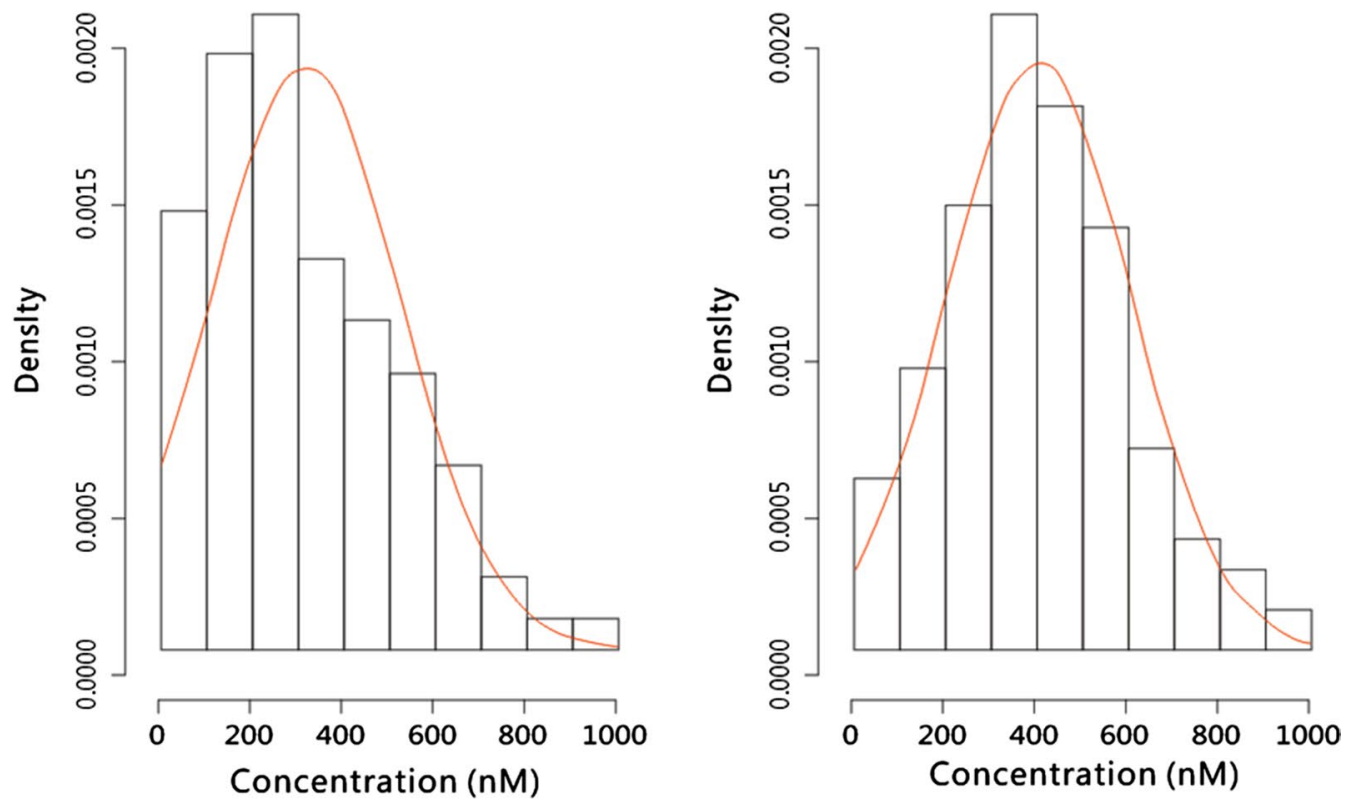

Fig. 6 Distribution and values of SAM and SAH calculated using R programming. a 81 normal serum samples; $\mathbf{b} 291$ diseased serum or plasma samples 


\section{Distribution of normal plasma SAM levels in different genders and age groups}

In another study of 310 plasma samples from the blood center, the ranges, averages, and standard deviations of SAM levels in females and males were analyzed, and the case numbers and percentages in each group are summarized in Table 4. On average, women had higher SAM levels $(296.92 \mathrm{nM})$ than men $(232.86 \mathrm{nM})$. Furthermore, a larger percentage of females had SAM levels exceeding $240 \mathrm{nM}$ than males (Table 4; Fig. 6), contributing to the higher average SAM levels determined in females. Table 5 shows the different ranges of SAM levels by age group. With increasing age, the percentage of people with SAM levels lower than $60 \mathrm{nM}$ increased from $1.46 \%$ among those aged $18-31$ years to $12.5 \%$ among those aged 51-60 years. However, with increasing age, the percentage of people with SAM higher than $240 \mathrm{nM}$ generally decreased, except in the age group from 51 to 60 years. The decrease in SAM levels with age might be attributable to the following factors: too few cases in the 51- to 60-year-old age group; the 31- to 50-yearold group is subject to higher life stress and the greatest workload in China (a relatively larger percentage of people aged 31-50 years old were considered to have a sub-healthy condition, which might be related to lower SAM levels); a significant proportion of people aged 51-60 years are retired and most likely find ways to take good care of their health and are under less stress. The results shown in Table 5 and Fig. 7 indicate that women have higher average SAM levels than men (approximately $28 \%$ higher). This discrepancy is likely not due to differences in diet, geographical area or social status. The fundamental reasons for these differences are unknown and are likely related to metabolism and genetic background. SAM levels were higher in females than in males, consistent with another study of 81 normal serum samples. The differences in SAM and SAH levels between the 310 plasma samples and 86 serum samples may be

Table 4 Distribution of normal human plasma SAM levels by gender

\begin{tabular}{lclcl}
\hline SAM (nM) & \multicolumn{2}{c}{ Male no. (\%) } & \multicolumn{2}{c}{ Female no. (\%) } \\
\hline$<30$ & 0 & 0 & 1 & 1.01 \\
$30-60$ & 9 & 4.2 & 3 & 3.03 \\
$60-120$ & 44 & 20.85 & 9 & 9.09 \\
$120-240$ & 70 & 33.18 & 33 & 33.33 \\
$240-480$ & 75 & 35.55 & 39 & 39.39 \\
$480-960$ & 13 & 6.16 & 14 & 14.14 \\
$>960$ & 0 & 0 & 0 & 0 \\
Avg. SAM & 211 & 232.86 & 99 & 296.92 \\
SD SAM & 211 & 149.56 & 99 & 185.12 \\
\hline
\end{tabular}

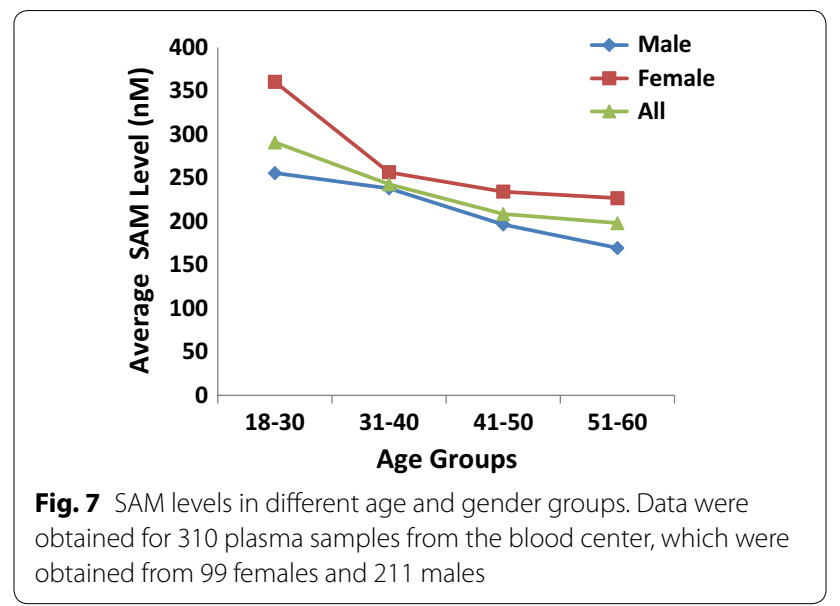

attributable to the prolonged period that the plasma was stored in the refrigerator before freezing.

Figure 7 shows the average SAM levels in different age and gender groups. In both genders, the SAM level continuously decreased with increasing age, indicating that SAM might be directly or indirectly involved in the aging process. Table 5 shows that a higher percentage of people older than 51 years had SAM levels of less than $60 \mathrm{nM}$, which indicates that older age was associated with decreased SAM levels. ANOVA analysis was performed with SAM, SAH and the MI as the response variables and age and gender groups as the explanatory variables. The $\mathrm{p}$ value was 0.0343 for the age group in terms of SAM (significant at level $\alpha=0.05$ ) and 0.0511 for the gender group in terms of SAM (significant at level $\alpha=0.1$ ). These results indicate that the decreasing SAM trends for age and gender, as shown in Fig. 7, are statistically significant but at different levels. The levels of SAM in females were significantly higher than those in males. In a normal population, the younger a person, the higher the level of SAM. The SAM level was significantly higher in the 18- to 30-year-old age group than in any other age group older than 31 years. The SAM level in children and youth younger than 18 years was not evaluated.

A previous report indicated global DNA hypomethylation in older individuals compared with a younger population. The data indicated that age-related variations in the global DNA methylation profile of leukocytes might be modulated by the daily intake of carbohydrates, lipids, vitamin B6, and magnesium and associated with serum protein levels. These nutritional factors may cause the SAM level to decrease greatly due to metabolic changes that occur as people age, contributing to the hypomethylation observed in the elderly population.

Men and women have different hormone levels and considerably different hormone compositions, and thus their metabolisms differ. Liver cells express estrogen 
Table 5 Distribution of normal human plasma SAM levels in different age groups

\begin{tabular}{|c|c|c|c|c|c|c|c|c|}
\hline \multirow{2}{*}{$\begin{array}{l}\text { SAM (nM) } \\
<30\end{array}$} & \multicolumn{2}{|c|}{ Age $18-30$ No. (\%) } & \multicolumn{2}{|c|}{ Age $31-40$ No. (\%) } & \multicolumn{2}{|c|}{ Age $41-50$ No. (\%) } & \multicolumn{2}{|c|}{$\begin{array}{l}\text { Age 51-60 No. } \\
\text { (\%) }\end{array}$} \\
\hline & 1 & 0.73 & 0 & 0 & 0 & 0 & 0 & 0 \\
\hline $30-60$ & 1 & 0.73 & 5 & 6.10 & 4 & 5.33 & 2 & 12.50 \\
\hline $60-120$ & 17 & 12.41 & 16 & 19.51 & 17 & 22.67 & 3 & 18.75 \\
\hline $120-240$ & 42 & 30.66 & 28 & 34.15 & 30 & 40 & 3 & 18.75 \\
\hline $240-480$ & 58 & 42.34 & 28 & 34.15 & 20 & 26.67 & 8 & 50 \\
\hline $480-960$ & 18 & 13.14 & 5 & 6.10 & 4 & 5.33 & 0 & 0 \\
\hline$>960$ & 0 & 0 & 0 & 0 & 0 & 0 & 0 & 0 \\
\hline$<60$ & 2 & 1.46 & 5 & 6.10 & 4 & 5.33 & 2 & 12.5 \\
\hline$>240$ & 76 & 55.47 & 33 & 40.25 & 24 & 32 & 8 & 50 \\
\hline Total no. & 137 & & 82 & & 75 & & 16 & \\
\hline
\end{tabular}

receptors that are related to development, lipid metabolism and insulin sensitivity, hepatic carcinogenesis, protection from drug-induced toxicity and fertility. In addition, estrogens can modulate growth hormone activity in the liver by acting centrally (pituitary growth hormone) and by modulating the GHR-JAK2-STAT5 pathway [39]. Age and gender affect metabolic syndrome and metabolic disorders in all-cause and cardiovascular disease-related mortality [40]. The Met cycle may be related to the pathways indicated above, and further investigations may elucidate the gender-dependent SAM level. A recent clinical trial assessing the efficacies of SAM for the treatment of depression in female and male patients indicated that gender might impact the antidepressant efficacy of SAM, with a greater therapeutic effect observed in males [41] only. The average lower level of SAM in males than in females may contribute to the underlying mechanisms.

\section{SAM and $\mathrm{MI}$ are reduced in disease Cancers}

Table 6 (after the Reference section) Study A shows the results of statistical analysis of data from cancer samples compared with normal serum samples by t-test. In liver cancers, SAH levels did not change significantly, and there was no significant change in the MI. By contrast, all other cancers exhibited a significant decrease in SAM levels and a significant increase in SAH levels, leading to more significant decreases in the MI, as indicated by the number of asterisks (*) for the t-test results. The dynamics of the levels of SAM and SAH in liver appear to differ from those in other tissues and organs. Our prior investigations using immunohistochemistry and flow cytometry to assess normal and malignant liver cell lines indicated that in cancer cells, both intracellular SAM and SAH are significantly reduced. Although this observation may only reflect SAM and SAH levels during a particular stage in each case of pathogenesis, it supports the unique characteristics of the MI in the liver compared to other tissues and organs, probably because SAM is primarily metabolized in the liver. The differences in SAH levels in liver cancers from other tissues or organs emphasize the importance of SAM measurements for describing the severity of liver disease.

\section{Liver diseases}

In a controlled study conducted at Xiangya Hospital, SAM levels were measured in patients with severe liver conditions such as acute viral hepatitis, cirrhosis, and liver failure. Patients who received SAM as a liver-protecting medicine were excluded from the study. We observed that SAM levels and the MI in different types of liver diseases, including hepatitis, carcinoma, cirrhosis and liver failure, were very different from those in the normal population. These findings were striking. Patients with hepatitis were diagnosed with acute severe viral hepatitis ( $B$ and C). Patients with cirrhosis were also in an advanced stage requiring aggressive treatments in the hospital. Liver failure indicated that liver functions could no longer be compensated, and laboratory results revealed a severe loss of liver function. In hepatitis, $19.57 \%$ of the 46 samples had SAM levels higher than $120 \mathrm{nM}$, in contrast to 95\% of normal samples; $4.35 \%$ had SAM levels greater than $240 \mathrm{nM}$, in contrast to $69.14 \%$ of the normal samples; and $94.87 \%$ of the 46 samples had an MI less than 0.5 , in contrast to $8.64 \%$ of the normal samples. Among patients with hepatocyte carcinoma, 4 of 14 (28.57\%) exhibited SAM levels greater than $120 \mathrm{nM}, 7.14 \%$ had SAM levels greater than $240 \mathrm{nM}$, and $85.71 \%$ had an MI less than 0.5. Among patients with cirrhosis, 3 of 20 (15\%) exhibited SAM levels greater than $120 \mathrm{nM}, 5 \%$ had SAM levels greater than $240 \mathrm{nM}$, and $89.47 \%$ had an MI of less than 0.5. Finally, all 19 patients with liver failure had SAM levels less than $120 \mathrm{nM}$ and an MI of less than 0.5. These 
Table 6 Results of $\boldsymbol{t}$ test in diseases from different studies

\begin{tabular}{|c|c|c|c|c|}
\hline Diseases & $\begin{array}{l}\text { Response } \\
\text { variable }\end{array}$ & Mean & $p$ value & Significance \\
\hline \multicolumn{5}{|l|}{ Study A } \\
\hline Liver cancer & SAM & 278.0652 & 0.03451 & $* *$ \\
\hline Liver cancer & $\mathrm{SAH}$ & 293.35 & 0.3288 & \\
\hline Liver cancer & $\mathrm{Ml}$ & 1.562109 & 0.1131 & \\
\hline Lung cancer & SAM & 262.5039 & 0.001248 & $* * *$ \\
\hline Lung cancer & $\mathrm{SAH}$ & 326.9877 & 0.007807 & $* * *$ \\
\hline Lung cancer & $\mathrm{Ml}$ & 0.9710702 & $3.67 \mathrm{E}-06$ & $* * * *$ \\
\hline Other cancer & SAM & 283.3233 & 0.00116 & $* * *$ \\
\hline Other cancer & $\mathrm{SAH}$ & 394.7301 & $5.61 \mathrm{E}-06$ & $* * * *$ \\
\hline Other cancer & $\mathrm{Ml}$ & 0.8156412 & $8.12 \mathrm{E}-09$ & $* * * *$ \\
\hline \multicolumn{5}{|l|}{ Study B } \\
\hline $\begin{array}{c}\text { Cerebrovascu- } \\
\text { lar diseases }\end{array}$ & SAM & 415.4277 & 0.6064 & \\
\hline $\begin{array}{l}\text { Cerebrovascu- } \\
\text { lar diseases }\end{array}$ & $\mathrm{SAH}$ & 363.3671 & 0.03015 & $* *$ \\
\hline $\begin{array}{c}\text { Cerebrovascu- } \\
\text { lar diseases }\end{array}$ & $\mathrm{Ml}$ & 1.163449 & $2.03 E-05$ & $* * * *$ \\
\hline Depression & SAM & 337.385 & 0.3531 & \\
\hline Depression & $\mathrm{SAH}$ & 442.379 & 0.01176 & $* *$ \\
\hline Depression & $\mathrm{Ml}$ & 0.87051 & 4.81E-06 & $* * * *$ \\
\hline $\begin{array}{l}\text { Parkinson's } \\
\text { disease }\end{array}$ & SAM & 285.5726 & 0.07684 & $*$ \\
\hline $\begin{array}{l}\text { Parkinson's } \\
\text { disease }\end{array}$ & $\mathrm{SAH}$ & 794.5792 & 0.06972 & * \\
\hline $\begin{array}{l}\text { Parkinson's } \\
\text { disease }\end{array}$ & $\mathrm{Ml}$ & 0.74988 & $7.18 \mathrm{E}-06$ & $* * * *$ \\
\hline \multicolumn{5}{|l|}{ Study C } \\
\hline $\begin{array}{c}\text { Cerebrovascu- } \\
\text { lar diseases }\end{array}$ & SAM & 357.9406 & 0.4365 & \\
\hline $\begin{array}{l}\text { Cerebrovascu- } \\
\text { lar diseases }\end{array}$ & $\mathrm{SAH}$ & 353.175 & 0.001237 & $* * *$ \\
\hline $\begin{array}{l}\text { Cerebrovascu- } \\
\text { lar diseases }\end{array}$ & $\mathrm{Ml}$ & 1.148035 & $2.31 \mathrm{E}-05$ & $* * * *$ \\
\hline Diabetes & SAM & 262.3474 & 0.001136 & $* * *$ \\
\hline Diabetes & $\mathrm{SAH}$ & 372.0686 & 0.003831 & $* * *$ \\
\hline Diabetes & $\mathrm{Ml}$ & 0.8619158 & $9.20 \mathrm{E}-08$ & $* * * *$ \\
\hline $\begin{array}{l}\text { High blood } \\
\text { pressure }\end{array}$ & SAM & 288.3645 & 0.0389 & $* *$ \\
\hline $\begin{array}{l}\text { High blood } \\
\text { pressure }\end{array}$ & $\mathrm{SAH}$ & 358.1118 & 0.01378 & $* *$ \\
\hline $\begin{array}{l}\text { High blood } \\
\text { pressure }\end{array}$ & $\mathrm{Ml}$ & 0.9178064 & $3.93 \mathrm{E}-07$ & $* * * *$ \\
\hline Heart diseases & SAM & 315.962 & 0.07938 & $* *$ \\
\hline Heart diseases & $\mathrm{SAH}$ & 440.9451 & $5.95 \mathrm{E}-07$ & $* * * *$ \\
\hline Heart diseases & $\mathrm{Ml}$ & 0.7822701 & $5.61 \mathrm{E}-09$ & $* * * *$ \\
\hline Inflammation & SAM & 223.732 & $3.05 E-06$ & $* * * *$ \\
\hline Inflammation & $\mathrm{SAH}$ & 292.012 & 0.2051 & \\
\hline Inflammation & $\mathrm{Ml}$ & 0.8193137 & $1.91 \mathrm{E}-08$ & $* * * *$ \\
\hline Kidney disease & SAM & 307.6073 & 0.1077 & \\
\hline Kidney disease & $\mathrm{SAH}$ & 497.1204 & 7.76E-06 & $* * * *$ \\
\hline Kidney disease & MI & 0.6976807 & 3.69E-09 & $* * * *$ \\
\hline
\end{tabular}

Table 6 continued

\begin{tabular}{|c|c|c|c|c|}
\hline Diseases & $\begin{array}{l}\text { Response } \\
\text { variable }\end{array}$ & Mean & $p$ value & Significance \\
\hline $\begin{array}{c}\text { Chronic liver } \\
\text { diseases }\end{array}$ & SAM & 356.3407 & 0.5037 & \\
\hline $\begin{array}{c}\text { Chronic liver } \\
\text { diseases }\end{array}$ & $\mathrm{SAH}$ & 444.0027 & $1.22 \mathrm{E}-06$ & $* * * *$ \\
\hline $\begin{array}{c}\text { Chronic liver } \\
\text { diseases }\end{array}$ & Ml & 0.8921861 & $2.72 \mathrm{E}-07$ & $* * * *$ \\
\hline $\begin{array}{c}\text { Respiratory } \\
\text { diseases }\end{array}$ & SAM & 393.3392 & 0.8827 & \\
\hline $\begin{array}{c}\text { Respiratory } \\
\text { diseases }\end{array}$ & $\mathrm{SAH}$ & 486.5144 & $4.24 \mathrm{E}-08$ & $* * * *$ \\
\hline $\begin{array}{c}\text { Respiratory } \\
\text { diseases }\end{array}$ & $\mathrm{Ml}$ & 0.7916811 & $5.27 \mathrm{E}-09$ & $* * * *$ \\
\hline
\end{tabular}

* Represents significance at significance level $=0.1,{ }^{* *}$ represents significance at significance level $=0.05 ;{ }^{* * *}$ represents significance at significance level $=0.01$, $* * * *$ represents significance at significance level $=0.001$

results demonstrate that SAM levels and MI values were significantly reduced compared with those in the normal controls; thus, SAM levels could be used as a biomarker to assist in the diagnosis of liver diseases.

\section{Brain diseases}

Table 7 presents the SAM and MI values of normal subjects (two different studies) and 40 cases of brain disease. The percentages of cases with SAM levels greater than $240 \mathrm{nM}$ was lower among cases of cerebrovascular disease, Parkinson's disease and depression compared with normal subjects. Moreover, among the cases of brain disease, there was a significant increase in the percentage of patients with an MI of less than 0.5 (8.64\% of normal people with $\mathrm{MI}<0.5$ from one study versus $20 \%$ of Parkinson's disease and depressed patients), and the percentage of patients with Parkinson's disease and depression patients with an MI greater than 1 was significantly lower than the percentage of normal subjects with an MI greater than 1. These findings suggest that MI might be a good marker of Parkinson's disease and depression, with a lower MI indicating a higher probability of Parkinson's disease or depression. The results of the t-test analyses of SAM, SAH and MI between normal and brain disease are shown in Table 6 Study B. The results demonstrated that SAM is decreased in cerebrovascular diseases, whereas the decrease in SAM in depression was not significant. However, the decreases in MI were very significant for all types of brain disease, suggesting that MI is a better biomarker for brain diseases.

\section{Other diseases}

Table 6 Study C shows the t-test results for other diseases versus normal serum controls. The decreases in SAM in cerebrovascular diseases, kidney diseases, chronic liver diseases, and respiratory diseases were not significant 
Table 7 SAM levels and MI values in brain diseases

\begin{tabular}{llllcc}
\hline Diseases (case \#) & \% of SAM $>\mathbf{2 4 0} \mathbf{n M}$ & $\mathbf{\%}$ of SAM > $\mathbf{1 2 0} \mathbf{~ M}$ & $\mathbf{\%}$ of $\mathbf{M I}>\mathbf{2}$ & $\mathbf{\%}$ of $\mathbf{M I}>\mathbf{1}$ & $\mathbf{\%}$ of $\mathbf{M I}<\mathbf{0 . 5}$ \\
\hline Normal plasma (310) & 90.36 & 96.79 & 6.95 & 42.47 & 16.98 \\
Normal serum (81) & 69.14 & 95.06 & 46.91 & 77.90 & 8.64 \\
Cerebral hemorrhage (10), embolism (6), infarction (4) & 85 & 90 & 0 & 65 & 0 \\
Parkinson's disease (10), depression (10) & 70 & 90 & 0 & 25 & 20
\end{tabular}

compared with the normal controls, whereas the increases in SAH in this diseases were significant. The levels of SAM decreased significantly in diabetes, high blood pressure, heart diseases and inflammation. However, the decreases in the MI were all extremely significant for all analyzed diseases, which suggests that the MI is a better biomarker for these diseases.

\section{SAM and inflammation}

Interesting results were obtained for the levels of SAM, SAH and MI under conditions of inflammation (Table 6 Study C). The levels of SAM were significantly reduced in inflammation conditions, whereas the increase in SAH in inflammation conditions was not significant. The diseases included in this inflammation group were mostly digestive, vascular and other benign inflammatory conditions. Common features of the group were chronic and widespread inflammatory responses. Thus, SAM appears to play a larger role in these conditions than SAH. This phenomenon is likely related to the important role of SAM in inflammatory processes in which internal strong anti-inflammatory factors such as spermine or spermidine or MTA are generated as a result of SAM aminopropylation. Under certain pathological conditions, SAM aminopropylation might be blocked or deficient due to reduced SAM levels, resulting in defective anti-inflammatory functions of SAM and uncontrolled inflammatory reactions. Accordingly, supplementation with SAM would, in most cases, control inflammation [42]. In North America, SAM pills are sold over-the-counter for the relief of joint pain or the treatment of osteoarthritis. The present study provided a foundation for the use of SAM for controlling inflammation.

\section{Ranges of the $\mathrm{MI}$}

Table 8 summarizes the ranges and averages of the MI for all diseases in this study. The findings are consistent with the results of $\mathrm{t}$-tests demonstrated that the MI is significantly higher in normal subjects (average value of 2.23) than diseased patients (average of 0.87 or $<1.56$ ). This clear difference between the normal and diseased groups is also apparent for the maximum MI. The MI value was between 4 and 6 in cancer, and therefore the average MI in cancer was relatively higher than that in other diseased
Table 8 Ranges and averages of MI values in different diseases

\begin{tabular}{lll}
\hline Group & Range of MI & Average MI \\
\hline Normal & $0.40-6.50$ & 2.23 \\
All diseases & $0.07-5.67$ & 0.87 \\
Cerebrovascular diseases & $0.36-5.67$ & 1.06 \\
Parkinson's Disease & $0.08-1.86$ & 0.75 \\
Depression & $0.36-1.94$ & 0.87 \\
Diabetes & $0.11-3.86$ & 0.86 \\
HBP & $0.10-1.19$ & 0.92 \\
Heart disease & $0.07-1.95$ & 0.78 \\
Inflammation & $0.28-2.13$ & 0.82 \\
Kidney disease & $0.10-1.92$ & 0.70 \\
Liver diseases & $0.22-2.50$ & 0.89 \\
Respiratory diseases & $0.13-1.49$ & 0.79 \\
Other cancers & $0.10-5.42$ & 0.81 \\
Liver cancer & $0.13-4.98$ & 1.56 \\
Lung cancer & $0.06-5.42$ & 0.68 \\
\hline
\end{tabular}

groups, primarily due to higher SAM levels in the in cancer samples. This result is consistent with an article by Greenberg et al. [43], who reported elevated serum SAM levels in patients with lung cancer compared with smokers with benign lung disorders and healthy nonsmokers. No significant correlations were identified between SAM levels and tumor cell types, nodule size, or other demographic variables. The transient high SAM levels may be caused by the release of intracellular SAM from cells into the blood stream (as confirmed by IHC staining of SAM from cancer cells (data not shown) during certain stages of cancer progression). Thus, we observed wide ranges of MI values in all types of cancers. SAM release was significant only in certain stages of cancer development. The release of SAM into the blood stream at high levels contributes to the large ranges in SAM levels observed in all cancers. An MI of 5.67 was detected in only one of 68 cerebrovascular disease samples. All other MIs were less than 2.09. If that sample is considered an outlier, the average MI for this group is less than 1 rather than 1.06. Therefore, cerebrovascular diseases should be considered among other diseases in evaluating the range and average value of the MI. 


\section{SAM and the $\mathrm{MI}$ as disease biomarkers}

If the antibodies used in the assays are specific, the MI measured by immunoassays carries greater weight than the MI measured based on free SAM and SAH alone. Because the free and complex forms of SAM and SAH are subject to enormous dynamics, a method that evaluates the complete profiles has obvious advantages over simply examining one subset. SAM, SAH and the MI were previously used as biomarkers for diagnosing acute rejection after renal transplantation and nephrotoxicity events [44]. The present work and other studies investigating Pneumocystis carinii pneumonia (PCP) in patients with HIV infection or other immunocompromised conditions [45] suggest that the measurement of SAM levels by cELISA could be an effective tool to diagnose the occurrence of PCP in immunocompromised conditions.

We evaluated SAM, SAH and MI levels in liver diseases in three different scenarios: (a) hepatocyte cancers (Table 6 Study A), (b) acute or severe liver diseases described in the liver disease section above, and (c) chronic liver disorders (Table 6 Study C). The results from (b) indicate that SAM and the MI can be used to identify severe liver diseases based on the significant decreases in these parameters. The cutoff value could be set between $120 \mathrm{nM}$ and $240 \mathrm{nM}$. Because SAM is actively generated and metabolized in the liver, deterioration of liver function will significantly affect SAM metabolism. The results from (c) indicate that a non-significant decrease in SAM might be related to milder and chronic liver conditions in which SAM might be compensated as part of liver functional compensation over time. The results from (a) demonstrate a significant decrease in SAM in liver cancer patients but no significant increase in SAH levels, suggesting differences in the disruption of the Met cycle between carcinogenesis and other pathological processes. The level of SAM in hepatic carcinoma was decreased significantly, in contrast to a report by $\mathrm{Li}$ [46]. The transient high levels of SAM were caused by the release of intracellular SAM from cells into the bloodstream (confirmed by immunohistochemistry staining of SAM in cancer cells, data not shown) at some stage of cancer progression. Because SAM release is only significant in certain stages of cancer development, after this release is complete, the elevated SAM levels in the bloodstream will not be maintained, contributing to the large ranges of SAM levels observed for all cancer types Our samples were collected from various stages of cancers, and therefore wide ranges of MI values were observed in the cancer samples. Table 8 also shows that the average MI for liver cancers was much higher than that for other diseases, indicating that in some liver cancers, the levels of SAM were high, which is consistent with Li's report. In conclusion, SAM is a biomarker of the stages or severity of liver diseases.
Although we did not exhaustively examine all disease types, the cases observed in the present study were derived from a variety of diseases, although some diseases were combined for analysis due to the small number of samples. The significant reduction of the observed in many disease types suggest that MI could serve as a useful biomarker for the evaluation of an individual's health status. Furthermore, the diseased group exhibited significantly lower SAM and MI levels and significantly elevated SAH levels compared to healthy people. MI can thus serve as a health status indicator. We believe the major use of the MI as a health marker would involve monitoring changes in the MI of an individual over time. MI can be used as a screening biomarker to detect an unfavorable health condition in humans, although further examinations are warranted for a final disease diagnosis. Further clinical investigations in different races and segments of the population stratified by age, gender, diet, medication or even genetic background are needed. The MI will likely be useful for aiding the detection of disease conditions in healthy populations and be included in annual health examination panels.

\section{Conclusions}

In the present study, monoclonal antibodies against SAM and SAH were characterized, and associated immunoassays were established. This preliminary investigation indicated that SAM, SAH and MI are good indicators of general health. In the absence of factors that may alter the value of the MI, such as special diets and medications, a significant reduction of the MI compared with an individual's baseline MI reference profile may suggest unfavorable conditions or diseases and warrant a visit to the doctor.

\section{Additional file}

Additional file 1. Information on cases collected from clinical labs.

\section{Authors' contributions}

$\mathrm{XH}$ directed all the experimental and research, designed the experiments, and performed data analysis, data integration, manuscript writing and proof-reading. $\mathrm{HR}$ and $\mathrm{HG}$ performed the generation of the monoclonal antibodies. $\mathrm{HL}$, $Y Z$ and $J X$ involved in the characterization of antibodies and establishment of cELISA; performed the sample measurement, figures creation, data integration and statistics. YH, WL, MQ, CY and LG carried out the sample collection and sorting. IA performed literature search, manuscript writing and proof-reading.

\section{Author details}

${ }^{1}$ Arthus Biosystems, 2600 Hilltop Dr., Richmond, CA 94806, USA. ${ }^{2}$ Hunan SkyWorld Biotechnologies Co. Ltd, 9 Panpan Rd. Changsha Economic and Technological Development Zone, Changsha, Hunan 410100, China. ${ }^{3}$ Department of Infectious Diseases, Xiangya Hospital, Central South University Hospital, Changsha, China. ${ }^{4}$ Department of Cardiology, Xuanwu Hospital, Capital Medical University, Beijing 100053, China. ${ }^{5}$ Changsha Blood Center, Changsha 410000, China. ${ }^{6}$ Lanwei Clinical Laboratories Co. Ltd., 268 Xinxing 
Rd. International Enterprise Center Building 9, Suite 301, Yuhua District, Changsha 410000 , China.

\section{Acknowledgements}

We acknowledge Dr. Huaitian Liu and Sydney Wong for their kindly contribution to statistical analysis and interpretation.

\section{Competing interests}

The author(s) declare that they have no competing interests.

\section{Availability of data and materials}

The datasets during and/or analyzed during the current study are available from the corresponding author on reasonable request. A part of data generated or analyzed during this study are included in this published article and its supplementary information file.

\section{Ethics approval and consent to participate}

The studies were approved by The Ethics Committee of Hunan SkyWorld Biotechnologies. Informed consent, written or verbal, was obtained from all participants.

\section{Funding}

Hunan Changsha Economic and Developmental Technology Zone Administrative Committee funded the studies and personnel.

\section{Received: 12 February 2016 Accepted: 15 November 2016}

Published online: 28 November 2016

\section{References}

1. Obeid J, Jung J, Falk J, Herrmann W, Geisel J, Friesenhahn-Ochs B, Lammert F, Fassbender K, Kostopoulos P. Serum vitamin B12 not reflecting vitamin B12 status in patients with type 2 diabetes. Biochimie. 2013;95:1056-61.

2. Shea TB. Effects of dietary supplementation with $\mathrm{N}$-acetyl cysteine, acetyl-L-carnitine and S-adenosyl methionine on cognitive performance and aggression in normal mice and mice expressing human ApoE4. NeuroMol Med. 2007:9(3):264-9.

3. di Padova C. S-adenosylmethionine in the treatment of osteoarthritis. Review of the clinical studies. Am J Med. 1987;83(supp 5A):60-5.

4. Tavoni A, Vitali C. Bombardieri, Pasero GS. Evaluation of S-adenosylmethionine in primary fibromyalgia. A double-blind crossover study. Am J Med. 1987:83(suppl 5A):107-10.

5. Alsayed R, Quobailia FAL, Srour S, Geisel J, Obeid R. Elevated dimethylglycine in blood of children with congenital heart defects and their mother. Metab Clin Exp. 2013;62:1074-80.

6. Dayal S, Bottiglieri T, Arning E, Maeda N, Malinow MR, Sigmund CD, et al. Endothelial dysfunction and elevation of S-adenosylhomocysteine in cystathionineb-synthase-deficient mice. Circ Res. 2001;88:1203-9.

7. Lu SC, Mato JM. S-adenosylmethionine in liver health, injury, and cancer. Physiol Rev. 2012;92:1515-42.

8. Lu SC, Mato JM. Role of methionine adenosyltransferase and S-adenosylmethionine in alcohol-associated liver cancer. Alcohol. 2005;35:227-34.

9. Coppedè $F$. The potential of epigenetic therapies in neurodegenerative diseases. Front Genet. 2014;5:1-8.

10. Guerra-Shinohara EM, Morita OE, Peres S, Pagliusi RA, Sampaio NLF, D'Almeida $V$, et al. Low ratio of S-adenosylmethionine to S-adenosylhomocysteine is associated with vitamin deficiency in Brazilian pregnant women and newborns. Am J Clin Nutr. 2004;80:1312-21.

11. Bell KM, Potkin SG, Carreon D, Plon L. S-adenosylmethionine blood levels in major depression: changes with drug treatment. Acta Neurol Scand Suppl. 1994;154:15-8.

12. Goodnick PJ, Sandoval R. Psychotropic treatment of chronic fatigue syndrome and related disorders. J Clin Psychiatry. 1993;54:13-20.

13. Seivwright C, Macnab JC, Adams RL. S-adenosylmethionine metabolism in herpes simplex virus type 2-infected cells. J Gen Virol. 1993;7:1405-7.

14. Shea TB, Chan A. S-adenosyl methionine: a natural therapeutic agent effective against multiple hallmarks and risk factors associated with Alzheimer's disease. J Alzheimers Dis. 2008;13:67-70.
15. Skelly M, Hoffman J, Fabbri M, Holzman RS, Clarkson AB Jr, Merali S. S-adenosylmethionine concentrations in diagnosis of Pneumocystis carinii Pneumonia. Lancet. 2003;361:1267-8.

16. Padova CD. S-adenosyl-L-methionine in the treatment of osteoarthritis: review of the clinical studies. Am J Med. 1987:83:60-5.

17. Kagan BL, Sultzer DL, Rosenlicht N, Gerner RH. Oral S-adenosylmethionine in depression: a randomized, double blind, placebo-controlled trial. Am J Psychiatry. 1990;147:591-5.

18. Bottiglieri T, Godfrey P, Flynn T, Carney MW, Toone BK, Reynolds EH. Cerebrospinal fluid S-adenosyl-L-methionine in depression and dementia: effects of treatment with parenteral and oral S-adenosyl-L-methionine. J Neurol Neurosurg Psychiatry. 1990;53:1096-8.

19. Bottiglieri T, Hyland K, Reynolds EH. The clinical potential of admetionine (S-adenosyl-I-methioinine) in neurological disorders. Drugs. 1994;48:137-52.

20. Morrison LD, Smith DD, Kish SJ. Brain S-adenosylmethionine levels are severely decreased in Alzheimer's disease. J Neurochem. 1996:67:1328-31.

21. Cheng H, Gomes-Trolin C, Aquilonius SM, Steinberg A, Löfberg C, Ekblom J, et al. Levels of L-methionine S-adenosyltransferase activity in erythrocytes and concentrations of S-adenosylmethionine and S-adenosylhomocysteine in whole blood of patients with Parkinson's disease. Exp Neurol. 1997;145:580-5

22. Mischoulon D, Fava M. Role of S-adenosyl-L-methionine in the treatment of depression: a review of the evidence. Am J Clin Nutr. 2002;76(5):1158S-61S.

23. Anstee QM, Day CP. S-adenosylmethionine (SAMe) therapy in liver disease: a review of current evidence and clinical utility. J Hepatol. 2012:57:1097-109.

24. Almasio P, Bortolini M, Pagliaro L, Coltorti M. Role of S-adenosyl-L-methionine in the treatment of intrahepatic cholestasis. Drugs. 1990:40:111-23.

25. Bressa GM. S-adenosyl-L-methionine (SAMe) as antidepressant: metaanalysis of clinical studies. Acta Neurol Scand Suppl. 1994;154:7-14.

26. Yokoyama S, Sells MA, Reddy TV, Lombardi B. Hepatocarcinogenic and promoting action of a choline-devoid diet in the rat. Cancer Res. 1985;45:2834-42

27. Rogers AE. Methyl donors in the diet and responses to chemical carcinogens. Am J Clin Nutr. 1995;61:659S-65S.

28. Poirier LA, Wilson MJ, Shivapurkar N. Carcinogenesis and DNA hypomethylation in methyl-deficient animals. Exp Biol Med. 1986;12:151-61.

29. Pogribny IP, Miller BJ, James SJ. Alterations in hepatic p53 gene methylation patterns during tumor progression with folate/methyl deficiency in the rat. Cancer Lett. 1997;115:31-8.

30. Cooney CA, Wise CK, Poirier LA, Ali SF. Methamphetamine treatment affects blood and liver S-adenosylmethionine (SAM) in mice: correlation with dopamine depletion in the striatum. Ann NY Acad Sci. 1998;844:191-200.

31. Perna AF, Ingrosso D, Zappia V, Galletti P, Capasso G, De Santo NG. Enzymatic methyl esterification of erythrocyte membrane proteins is impaired in chronic renal failure. Evidence for high levels of the natural inhibitor S-adenosylhomocysteine. J Clin Invest. 1993:91:2497-503.

32. Suma Y, Matsumoto C, Sawai Y, Tsukada K. A sensitive assay method for the measurement of S-adenosylmethionine in tissue. J Biochem. 1984;96:679-82.

33. Mudd SH. Activation of methionine for transmethylation. VI. Enzymebound tripolyphosphate as an intermediate in the reaction catalyzed by the methionine-activating enzyme of Baker's yeast. J Biol Chem. 1963;238:2156-63.

34. Loehrer FM, Angst CP, Brunner FP, Haefeli WE, Fowler B. Evidence for disturbed S-adenosylmethionine: s-adenosylhomocysteine ratio in patients with end-stage renal failure: a cause for disturbed methylation reactions? Nephrol Dial Transplant. 1998;13:656-61.

35. Klepacki J, Brunner N, Schmitz V, Klawitter J, Christians U, Klawitter J. Development and validation of an LC-MS/MS assay for the quantification of the transmethylation pathway intermediates S-adenosylmethionine and S-adenosylhomocysteine in human plasma. Clin Chim Acta. 2013;421:91-7

36. Borman S. Heated dispute over analytical method. 2015. http://cen. acs.org/articles/93/i42/Heated-Dispute-Over-Analytical-Method.html. Accessed 23 Oct 2015. 
37. Köhler G, Milstein C. Continuous cultures of fused cells secreting antibody of predefined specificity. Nature. 1975;256(5517):495-7.

38. Wagner C, Koury MJ. S-adenosylhomocysteine: a better indicator of vascular disease than homocysteine? Am J Clin Nutr. 2007;86:1581-5.

39. Mirecki-Garrido MD, Guerra B, Mateos-Díaz C, Jiménez-Monzón R, DíazChico N, Díaz-Chico JC, et al. The influence of estrogens on the biological and therapeutic actions of growth hormone in the liver. Pharmaceuticals. 2012;5:758-78.

40. Wang WS, Wahlqvist ML, Hsu CC, Chang HY, Chang WC, Chen CC. Ageand gender-specific population attributable risks of metabolic disorders on all-cause and cardiovascular mortality in Taiwan. BMC Public Health. 2012;12:111.

41. Sarris J, Price LH, Carpenter LL, Tyrka AR, Ng CH, Papakostas Gl, Jaeger A, Fava M, Mischoulon D. Is S-adenosyl Methionine (SAMe) for depression only effective in males? A re-analysis of data from a randomized clinical trial. Pharmacopsychiatry. 2015;48(4-5):141-4.

42. Najm Wl, Reinsch S, Hoehler F, Tobis JS, Harvey PW. S-adenosyl methionine (SAMe) versus celecoxib for the treatment of osteoarthritis symptoms: a double-blind cross-over trial. BMC Musculoskelet Disord. 2004;5:6-20.
43. Greenberg AK, Rimal B, Felner K, Zafar S, Hung J, Eylers E, et al. S-adenosylmethionine as a biomarker for the early detection of lung cancer. Chest. 2007;132:1247-52.

44. Klepacki J, Brunner N, Schmitz V, Klawitter J, Christians U, Klawitter J. Development and validation of an LC-MS/MS assay for the quantification of the trans-methylation pathway intermediates S-adenosylmehtionine and S-adenosylhomocysteine in human plasma. Clin Chim Acta. 2013;421:91-7

45. Skelly MJ, Holzman RS, Meral S. S-adenosylmethionine levels in the diagnosis of Pneumocystis carinii Pneumonia in patients with HIV pnfection. Clin Inf Dis. 2008;46:467-71.

46. Li T, Yu G, Guo T, Qi H, Bing Y, Xiao Y, et al. The plasma S-adenosylmethionine level is associated with the severity of Hepatitis B-related liver disease. Medicine. 2015;94:1-8.

\section{Submit your next manuscript to BioMed Central and we will help you at every step:}

- We accept pre-submission inquiries

- Our selector tool helps you to find the most relevant journal

- We provide round the clock customer support

- Convenient online submission

- Thorough peer review

- Inclusion in PubMed and all major indexing services

- Maximum visibility for your research

Submit your manuscript at www.biomedcentral com/submit 